\title{
TESTE DE USABILIDADE DO MÓDULO DE ATENDIMENTO DA FERRAMENTA DESKTOP DE GESTÃO DE CLÍNICAS DE DIAGNÓSTICO POR IMAGEM, UNICLINIKA RIS.
}

\author{
Cecília Eloy Neves (1); \\ Fábio Campos, Ph.D. (2) \\ Universidade Federal de Pernambuco, Cecília Eloy Neves \\ e-mail: ceciliaeloyneves@gmail.com \\ Universidade Federal de Pernambuco, Prof. Fábio Campos, Ph.D. \\ e-mail: fc2005@gmail.com
}

\begin{abstract}
RESUMO
Com o crescimento do mercado digital, as empresas de Tecnologia da Informação veem uma necessidade crescente de investir em design e usabilidade. Com os softwares disponíveis, os usuários tornaram-se mais intolerantes e exigentes ao que usar e consumir. Na área de saúde não é diferente, novas tecnologias também estão surgindo tornando um mercado acirrado. Com esse novo mercado, tecnologia para a área de saúde, o UniClinika RIS foi desenvolvido. Seguindo princípios de usabilidade de Jordan, Leventhal e Barnes e as heurísticas de Nielsen, a ferramenta foi avaliada e problemas de usabilidade foram listados para serem apresentados à empresa desenvolvedora.
\end{abstract}

Palavras-chave: usabilidade, teste de usabilidade, heurística, princípios de usabilidade, UniClinika RIS

\section{ABSTRACT}

With the growth of the digital market, Information Technology companies see a growing need to invest in design and usability. With the available software, users have become more intolerant and demanding to use and consume. In the area of health having no different, new technologies are also emerging becoming a tight market. With this new market, technology for health, the UniClinika RIS was developed. Following principles of usability from Jordan, Leventhal and Barnes and Nielsen heuristics, the tool was evaluated and usability issues were listed to be presented the developer company.

Keywords: usability, usability testing, heuristic, usability principles, UniClinika RIS 


\section{INTRODUÇÃO}

Os celulares e computadores tornaram-se, ao longo dos anos, ferramentas indispensáveis para a vida pessoal e profissional da população. $O$ uso frequente de tais ferramentas fez surgir um novo mercado, o dos artefatos digitais. Com o crescimento do mercado digital, as empresas de TI (Tecnologia da Informação) veem a necessidade, cada vez maior, de investir em design e usabilidade. Com a competitividade no mercado e opções de ferramentas disponíveis, os usuários tornaram-se mais intolerantes e exigentes ao que usar e consumir.

A relação da tecnologia com a saúde vai desde maquinários de exames e cirurgias até o auxílio em tarefas mais simples, como agendar um exame por meio de dispositivos desktop e móveis. Apesar do crescente número de ferramentas digitais disponíveis para auxiliar as clínicas e hospitais, muitos ainda optam pela tradicional agenda de papel.

A tendência é cada vez surgirem mais soluções voltadas à gestão de clínicas e hospitais. Foi com esse novo âmbito de mercado que a empresa Ávila Soluções viu a necessidade de criar um produto de gerenciamento de clínicas por imagem que atendesse a todas as necessidades da clínica, assim surge o UniClinika RIS.

Com o intuito de melhorar a usabilidade do sistema para que o usuário fique mais satisfeito com ao usá-lo, a ferramenta desktop UniClinika RIS será avaliada seguindo três princípios de usabilidade que terão seus resultados comparados entre si. Assim como uma pesquisa com os usuários que também fará parte da análise. $E$ ao final, problemas encontrados na ferramenta, segundo a análise de usabilidade e pesquisa com os usuários, serão listados para que sejam solucionados.

\section{PROCEDIMENTOS METODOLÓGICOS}

\subsection{Tipologia e Estruturação do Projeto}

O trabalho aqui descrito pode ser caracterizado como um estudo descritivo. Segundo Best apud Marconi e Lakatos (2006) a pesquisa descritiva delineia o fenômeno estudado abordando quatro aspectos: descrição, registro, análise e interpretação dos fenômenos atuais, objetivando seu funcionamento. Para Santos et al (2011) estudos descritivos estão relacionados principalmente a perguntas do tipo "o que". Estudos avaliativos na área da usabilidade, de modo geral, podem ser considerados pesquisas descritivas.

O trabalho foi desenvolvido através das seguintes etapas:

- Descrição do Módulo de Atendimento da ferramenta UniClinika RIS, a versão mais recente implantada a um ano. Sobre as funções do módulo, foram escolhidas para a análise as funções de cadastrar novos pacientes, cadastrar novo médico solicitante e agendar exame, por serem as principais funções utilizadas pelo usuário;

- Análise de usabilidade da ferramenta conforme os princípios de Patrick Jordan (1998), por ser um dos principais princípios utilizados em ergonomia e usabilidade; 
- Análise de usabilidade da ferramenta conforme os princípios de Leventhal e Barnes (2008), por ser um dos mais novos princípios acaba por abranger tanto produtos como artefatos digitais. Princípio muito completo e utilizado para avaliação de artefatos digitais;

- Realização da Avaliação Heurística de Nielsen (1993), um dos primeiros princípios a surgir e que serviu de base para a criação do princípio de Jordan e de Leventhal e Barnes, anteriormente citados;

- Participação de treinamentos oferecidos pela empresa Ávila Soluções, criadora da ferramenta, aos clientes com o intuito de observar a relação dos usuários com a ferramenta, suas principais dúvidas e reclamações. Ao final, aplicar um questionário:

- Questionário misto aos usuários diários da ferramenta após o treinamento com a seguinte estrutura (Anexo 1 - Questionário com usuários diários):

1-Perfil do usuário (idade, sexo, experiência com o produto,...).

2-Informações sobre o uso - opiniões sobre possíveis dificuldades de manuseio e compreensão, identificação dos comandos, e questões relativas à satisfação de uso pelo SUS - System Usability Scale de John Brooke (1986). O SUS mede as opiniões do usuário, através de 10 questões fechadas e uma aberta, e utiliza a escala de avaliação "Likert" - 1 discordo plenamente, 2 discordo, 3 neutros, 4 concordo e 5 concordo plenamente. Gera um resultado global está inserido numa escala de 0 a 100. As 10 questões avaliam:

a-Frequência de uso do sistema;

b-Complexidade do sistema;

c-Facilidade de uso;

d-Assistência para usar o sistema;

e-Funções integradas do sistema;

f-Inconsistência do sistema;

g-Rápida aprendizagem;

h-Sistema é incômodo e complicado para usar;

i-Segurança e confiança para usar o sistema;

j-Aprendizagem de outras informações para usar o sistema.

- Análise da realização das tarefas pelos usuários inexperientes com aplicação de medição de desempenho, tendo como roteiro da observação direta: 10 realização das tarefas pré-determinadas pelo avaliador (cadastrar novo paciente, cadastrar novo médico solicitante e agendar exame); 20 o registro do tempo das operações e 30 a aplicação do questionário; 
- Aplicação de questionário misto aos usuários inexperientes da ferramenta com a seguinte estrutura (Anexo 2 - Questionário com usuários inexperientes):

1-Perfil do usuário (idade, sexo, experiência com o produto,...).

2-Questões relativas à satisfação de uso pelo SUS - System Usability Scale de John Brooke (1986).

- Comparar os resultados obtidos a partir dos princípios e heurística, juntamente com os obtidos durantes os treinamentos, análise da tarefa com usuários inexperientes e questionários aplicados.

\subsection{Ambiente e Sujeito da Pesquisa}

O ambiente do treinamento foi o Instituto José Rocha de Sá localizado do Derby. Com usuários da área de Call Center da clínica que utilizam o módulo de atendimento diariamente. Detalhes da clínica:

\section{Instituto José Rocha de Sá - Derby;}

Especialidade: Clínica de diagnóstico por imagem;

Atividades: Exames de diagnóstico por imagem;

Utilizado por: Funcionárias do call center e recepcionistas da clínica;

Amostra: 3 funcionários da área de call center.

Persona 1: Mulher de 35 anos, profissional de Call Center de clínicas de exame de diagnóstico por imagem. Com ensino fundamental completo. Trabalha 8 horas diárias, não é casada e não tem filho. Depende de transportes públicos para ir ao trabalho e voltar para casa. Mulher habituada a trabalhar com agenda de papel e que não aceita facilmente mudanças. Usuária diária do módulo de atendimento do UniClinika RIS.

A análise da tarefa pelo usuário inexperiente e aplicação de teste de medição de desempenho foi realizada na empresa Ávila Soluções com colaboradores da empresa que não estavam habituados a usar a ferramenta UniClinika. Detalhes da empresa:

\section{Ávila Soluções - Tamarineira;}

Especialidade: Tecnologia da Informação (TI);

Atividades: Soluções tecnológicas utilizando ferramenta Microsoft;

Funcionários: 5 diretores, 2 colaboradoras da área administrativa e financeira e 25 colaboradores da área de tecnologia

Suporte da ferramenta por: 3 colaboradores

Amostra: 10 colaboradores 
Persona 2: Homem de 35 anos, analista de sistema da empresa Ávila Soluções. Com ensino superior incompleto, trabalha 8 horas diárias, conta com carro próprio para ir e voltar do trabalho. Habituado a trabalhar com computador e softwares diversos. Aberto a mudanças, se for para facilitar e agilizar seu trabalho. Não utiliza o UniClinika RIS em seu dia a dia.

\subsection{Conceitos}

\section{Usabilidade}

A qualidade de uma interface pode ser medida para avaliar se é apropriada para o usuário ou a tarefa para a qual foi desenvolvido. A usabilidade é definida, pela ISO 9241- 11, como: "Usabilidade é o alcance pelo qual um produto pode ser usado por certos usuários para atingir objetivos específicos com eficácia, eficiência e satisfação em certo contexto de uso.".

Segundo o livro de Itiro lida (2005), usabilidade (neologismo traduzido do inglês usability) significa facilidade e comodidade no uso dos produtos, tanto no ambiente doméstico como no profissional. Itiro descreve uma boa usabilidade os produtos e artefatos "amigáveis" aos usuários. Os produtos devem ser fáceis de manusear, intuitivos e pouco sensíveis a erros, gerando uma maior satisfação para o usuário.

\section{Princípios de Usabilidade de Jordan (1998)}

\section{$\underline{1^{\circ}-\text { Evidência: }}$}

A solução formal do produto deve indicar claramente a sua função e o modo de operação.

\section{$\underline{2^{\circ}-\text { Consistência: }}$}

As operações semelhantes devem ser realizadas de forma semelhante. Isso permite que o usuário faça uma transferência positiva da experiência anteriormente adquirida em outras tarefas semelhantes.

\section{$\underline{3^{\circ}-\text { Capacidade: }}$}

O usuário possui determinadas capacidades para cada função, que devem ser respeitadas. Essas capacidades não devem ser ultrapassadas.

\section{$\underline{4^{0}-\text { Compatibilidade: }}$}

O atendimento às expectativas do usuário melhora a compatibilidade. Essas expectativas dependem de fatores fisiológicos, culturais e experiências anteriores.

\section{$\underline{5^{\circ} \text { - Prevenção e correção dos erros: }}$}

Os produtos devem impedir os procedimentos errados. Se estes ocorrerem, devem permitir uma correção fácil e rápida.

$\underline{6^{\circ}-\text { Realimentação: }}$ 
Os produtos devem dar um retorno aos usuários sobre os resultados de sua ação. Isso pode ser simples "bip" indicando que um comando foi acionado.

\section{Avaliação Heurística de Nielsen (1993)}

- Simplicidade e naturalidade de diálogo: As informações devem ser apresentadas de forma lógica, clara, natural e objetiva.

- Correspondência entre a linguagem do sistema e a do usuário: As informações contidas no sistema devem apresentar um diálogo claro e familiar;

- Minimizar a carga de memória do usuário: A interface deve ser coerente e apresentar linguagem unificada fazendo com que a carga da memória do usuário seja minimizada;

- Consistência: Deve existir uma consistência e padronização dos dados, prevenindo assim que o usuário faça uma errônea interpretação.

- Feedback: É necessário que o sistema apresente um feedback imediato das ações realizadas, mantendo o usuário informado a cerca do sistema;

- Saídas claramente identificadas: O sistema deve fornecer diversas formas de saídas para qualquer possível problema que possa vir acontecer;

- Atalhos: Os atalhos do sistema servem para otimizar e acelerar o processo de reutilização do mesmo;

- Mensagem de erro: As mensagens de erros devem ser expressas de forma clara e objetiva, indicando precisamente qual é o problema e fornecer uma solução construtiva para o mesmo.

- Prevenção de erros: Ao projetar o sistema deve-se atentar a prevenção de possíveis erros que possam vir a acontecer durante a realização de determinadas tarefas.

- Ajuda e documentação: O sistema deve fornecer ajuda ao usuário quando necessário, com informações claras e precisas, focando nas tarefas do usuário em questão.

\section{Princípios de Leventhal e Barnes (2008)}

Variável situacional - tarefa

a. Frequência: Tarefas que são desempenhadas frequentemente são plausíveis de incluir sequências já aprendidas pelo usuário;

b. Rigidez: O número de caminhos (escolhas) percorridos através da tarefa.

c. Limitações da situação: As variáveis das limitações da situação representam variáveis da tarefa que podem ser críticas para o sucesso ou falha de uma interface.

Variável situacional - usuário 


\section{a. Expertise}

i. Usuários experientes

ii. Usuários novatos

iii. Usuários ocasionais

b. Motivação: Os usuários com alta motivação podem ser mais propensos a completar uma tarefa, mesmo que a interface seja difícil.

Características de interface

a. Facilidade de aprendizagem: O quanto a interface é fácil de aprender para os novos usuários.

b. Facilidade de uso: O quanto a interface é fácil de operar.

c. Facilidade de reaprendizagem: O quanto a interface é fácil de usar uma vez após ter sido aprendida.

d. Adequação à tarefa: Uma tarefa bem adequada pode ajudar o usuário experiente ou novato em mapear a sua compreensão da interface da tarefa real.

e. Flexibilidade: Refere-se à capacidade da interface em apoiar novas ou inesperadas mudanças na tarefa. Ex. Caixa de supermercado.

f. Satisfação do usuário: É a resposta do usuário para a avaliação da discrepância entre as expectativas percebidas (ou alguma outra norma de desempenho) e o desempenho atual de um produto ou sistema percebido após o seu uso.

\section{ESTUDO DE CASO - UNICLINIKA RIS}

O UniClinika é uma ferramenta de gestão para clínicas de diagnóstico por imagem. A ferramenta conta com sete módulos (Agendamento, UniFinanças, Faturamento, Estoque, UniUser, Gestor e Cobranças) que atuam em áreas pontuais da clínica, desde o agendamento de paciente até a gestão de contas a pagar e a receber.

Cada Módulo atua em uma área da clínica e consequentemente são operados por usuários distintos. É o produto mais completo que existe no mercado por atuar em todas as áreas da clínica.

Entendendo os módulos do UniClinika como um único sistema, onde são interligados e dependentes um do outro, podemos dizer que existe um fluxo de atividade onde cada módulo depende do outro para existir (Anexo 3 - Fluxograma UniClinika RIS). A ferramenta visa expandir para o universo mobile, facilitando o agendamento do paciente.

\subsection{Módulo de Atendimento}

O módulo de atendimento é o primeiro módulo utilizado no sistema UniClinika RIS e o escolhido para a análise de usabilidade. Há um ano uma nova versão desse módulo foi implantada aos clientes na qual a avaliação será realizada. É utilizado por funcionários da recepção e do call center das clínicas.

\section{Funcionalidades:}


- Gerenciamento completo de agenda com vários filtros específicos;

- Reserva para pré-agendamentos;

- Confirmação de agendas por SMS;

- Processos customizados por tipo de consulta;

- Agenda por tipo de convênio;

- Detalha o ticket médio que cada médico pode produzir realizando o agendamento conforme produtividade aproximada;

- Cadastro rápido do Paciente (Facilitando o agendamento e o pré-cadastro);

- Gestão de filas;

- Tempo de atendimento;

- Resultado de exames;

- Atualização do cadastro;

- Fluxo de encaminhamento paciente;

- Pré-autorização de exames;

- Templates de questionários customizados para exames específicos;

- Controle de produtividade;

- Histórico do paciente;

- Personalização de Templates para laudos, rotinas e prescrições;

- Visualização rápida da fila de atendimento;

- Gravação de áudio no laudo;

- Assinaturas digitais;

\subsubsection{Análise da Tarefa}

Por possui uma variedade de funcionalidades, listadas anteriormente, decidi focar nas tarefas mais frequentes que os usuários realizam (Cadastro de pacientes, Cadastro de Solicitante e Agendamento de exames). Nesta etapa as tarefas selecionadas foram destrinchadas para melhor entendimento do funcionamento:

\section{Módulo Atendimento - Cadastrar o paciente}

Objetivo: Cadastrar novos pacientes para exames futuros.

Passos ou ações para realizá-la: Abrir o módulo de atendimento e clicar em "Pacientes". O usuário será redirecionado à tela de filtro de pacientes e na parte superior do lado esquerdo tem um ícone "Novo", o usuário irá clicar e ser redirecionado ao formulário de cadastro do paciente.

\section{Módulo Atendimento - Cadastrar Solicitante}

Objetivo: Cadastrar novo solicitante do exame.

Passos ou ações para realizá-la: Abrir o módulo de atendimento e clicar em "Solicitante". O usuário será redirecionado à tela de filtro de pacientes e na parte superior do lado esquerdo tem um ícone "Novo", o usuário irá clicar e ser redirecionado ao formulário de cadastro do solicitante.

\section{Módulo Atendimento - Agendar Exame}

Objetivo: Agendar exames. 
Passos ou ações para realizá-la: Abrir o módulo de atendimento e clicar em "Recepção". O usuário será redirecionado à tela de filtro de pacientes e na parte superior do lado esquerdo tem um ícone "Novo", o usuário irá clicar e ser redirecionado ao formulário agendar exame. Outro caminho seria clicando em "Agendamento", o primeiro com ícone de calendário, selecionar a agenda do médico, setor ou por sala. Aparecerá o calendário com os horários vagos da semana, ou dia, caso escolha a visualização por dia, e com um duplo clique a página de filtrar paciente irá aparecer. Depois do paciente selecionado, a ficha de agendamento será aberta para ser preenchida. Pelo outro ícone de "Agendamento", o com o ícone de calendário e um relógio, também é possível agendar. O médico executante deve ser selecionado, os horários aparecerão e é possível selecionar o horário e clicar em "Novo". A tela de selecionar paciente será aberta e quando selecionado, a ficha de agendamento será aberta.

\section{TESTE DE USABILIDADE E ANÁLISES}

\subsection{Pré-Diagnóstico de Usabilidade}

Análise realizada pela avaliadora antes do resultado dos questionários e análise da tarefa.

\subsubsection{Pré-diagnóstico segundo os Princípios de Jordan (1998)}

Evidência - Atende em parte ao princípio: $O$ nome do módulo descreve bem sua funcionalidade, mas o ícone não, pois é a imagem de um estetoscópio. Os ícones internos atendem ao entendimento do usuário, mas os termos geram confusão.

Consistência - Atende em parte ao princípio: Apesar de os nomes dos ícones, às vezes, não condizerem com a funcionalidade principal o módulo oferece vários caminhos para realizar as tarefas sem precisar fechar e abrir outra janela.

Capacidade - Atende em parte ao princípio: A falta de filtros e informações de campos e termos não facilita a agilidade na hora de agendar um exame.

Compatibilidade - Não atende ao princípio: Os usuários do módulo de atendimento tem como modelo mental a agenda de papel, em geral. Mesmo facilitando o agendamento, o módulo ainda obriga o usuário a decorar ou imprimir os horários dos médicos por falta de visualizações e filtros no sistema.

Prevenção e Correção de erros - Atende totalmente ao princípio: A ferramenta é composta de regras de agendamento que não permitem, por exemplo, que mais de um agendamento sejam feitos no mesmo horário.

Realimentação - Não atende ao princípio: Os feedbacks da ferramenta não existem.

\subsubsection{Pré-diagnóstico segundo os Princípios de Leventhal e Barnes (2008)}

Frequência - Atende totalmente ao princípio: No módulo de atendimento, temos uma boa separação das tarefas, tarefas semelhantes estão próximas e nem sempre é preciso abrir outra tela para realizar outra tarefa. 
Rigidez - Atende totalmente ao princípio: Levando em consideração as necessidades do usuário, o módulo fornece os caminhos necessários e sem muita complexidade.

Limitações da situação - Atende em parte ao princípio: Muitas abreviações e siglas são usadas, mas não apresentam uma explicação clara para cada termo.

Expertise - Atende em parte ao princípio: O programa segue a estrutura de outros programas desktop. Assim como segue os termos médicos. Mas alguns termos não são claros quando se trata de identificar a tarefa que será realizado em cada tela.

Motivação - Atende totalmente ao princípio: O usuário tem que usar o programa para trabalhar e eles entendem que vai facilitar o trabalho deles.

Facilidade de aprendizagem - Atende em parte ao princípio: Ainda que as tarefas não tenham um passo a passo complexo, requer um treinamento prévio.

Facilidade de uso - Atende em parte ao princípio: A falta de informações, feedbacks e termos/siglas/pictogramas não intuitivos prejudicam a facilidade de uso.

Facilidade de reaprendizagem - Atende totalmente ao princípio: A Ávila Soluções oferece treinamento e, uma vez aprendido, os usuários conseguem realizar as tarefas.

Adequação à tarefa - Atende em parte ao princípio: O programa tem uma boa divisão, onde é fácil de localizar e aprender o caminho da tarefa. Só as nomenclaturas que podem confundir de início.

Flexibilidade - Atende totalmente ao princípio: O programa deixa sempre o menu superior à vista, independente da janela que abra. O ícone de fechar a janela está sempre visível, assim como existem abas na parte inferior que mostram as janelas que estão abertas para que o usuário possa acessar sem problemas.

Satisfação do usuário - Atende em parte ao princípio: O programa oferece todos os recursos para o usuário realizar todas as suas tarefas de forma mais fácil, mas não é intuitivo e não oferece todas as visualizações e filtros necessários.

\subsubsection{Pré-diagnóstico segundo a avaliação heurística de Nielsen (1993)}

Diálogo simples e natural - Atende em parte: Para realizar as tarefas o percurso é simples e são oferecidos vários caminhos para realizar a mesma tarefa, mas as informações não são claras e há uma poluição de elementos que muitas vezes não são necessários.

Fale a linguagem do usuário - Atende em parte: Os ícones e termos utilizados são comuns, com alguns termos médicos, mas que para o usuário não é um problema. Mas não são claros e não tem uma explicação de cada termo, o que acaba gerando dúvida.

Minimize a carga de memória do usuário - Não atende: Informações não são claras, os usuários ainda dependem de memorizar algumas informações para agilizar o processo, por conta da falta de visualizações simplificadas e filtros. 
Consistência - Atende em parte: O módulo oferece vários caminhos para realizar as tarefas sem precisar fechar e abrir outra janela. Mas os caminhos alternativos não são claros e nem sempre o usuário consegue perceber.

Feedback - Não atende: Não existem feedbacks claros, o usuário finaliza a tarefa sem saber se deu certo ou não.

Saídas marcadas claramente - Atende totalmente: Independendo da tela que for acessada, o menu superior sempre está a vista e uma barra inferior com as telas abertas também é mostrada. Em todas as telas é possível "Cancelar" e "Fechar" a ação sem dificuldades, assim como mudar de tela facilmente e intuitivamente.

Atalhos - Atende totalmente: Apesar de alguns ícones gerarem confusão e dúvida, todas as áreas da ferramenta são de fácil acesso, pois existem ícones para todas elas.

Boas mensagens de erro - Atende em parte: Apesar de não mostrar, na ficha cadastral, quais informações são obrigatórias no preenchimento, às mensagens de erro são diretas, sempre mostrando o que falta ser preenchido para que a atividade seja realizada.

Prevenção de erros - Atende em parte: Oferece caminhos para todas as telas e funcionalidades de forma fácil e intuitiva, mas peca na hora de fornecer instruções aos usuários.

Ajuda e documentação - Não atende: Não existe um ícone de ajuda nem instruções nas telas de como realizar as tarefas.

\subsection{Resultado dos Questionários e Registros}

\subsubsection{Persona 1 - Treinamento}

O primeiro registro foi feito no dia 05 de maio de 2016 durante um treinamento oferecido pela empresa criadora do UniClinika para apresentar as novas funcionalidades do Módulo de Atendimento aos usuários diários do cliente Instituto José Rocha de Sá, Derby, Recife/PE.

Participaram do treinamento três funcionárias da área de call center na clínica, assim como dois funcionários da área de suporte e um da diretoria. O treinamento durou cerca de $1 \mathrm{~h} 30 \mathrm{~min}$. Tal visita tinha como intuito apresentar apenas as novas funcionalidades, mas alguns erros do sistema e problemas enfrentados no dia a dia dos usuários foram levantados também.

Foi possível perceber que, apesar das novas funcionalidades já estarem implantadas na clínica a cerca de um ano, não eram utilizadas. Este fato pode ser explicado porque as novas funcionalidades não foram aplicadas no programa existente. Criaram outro módulo de atendimento com os novos recursos e os usuários da clínica não se preocupavam em utilizar, por já estarem habituados ao antigo. E mesmo após o treinamento, não se mostraram muito empolgados com o novo módulo.

Após o treinamento, um questionário foi aplicado às três funcionárias de call center com os quais obteve-se os seguintes resultado. Todas consideraram o treinamento importante e até imprescindível para a realização da tarefa, mostrando que a 
ferramenta não é intuitiva. E que consideram que a quantidade de informações e legibilidade é um problema do sistema. Sobre o layout se consideraram neutras.

Resultado da Tabela SUS: O resultado do sistema SUS (System Usability Scale) recolhido com estes questionários foram de uma média de 28,33 . O resultado foi obtido com a média aritmética dos resultados de cada questionário, sendo eles 32,5 , $40,12,5$ pontos.

\subsubsection{Persona 2 - Análise da tarefa}

O segundo registro foi realizado na empresa Ávila Soluções durante a avaliação do módulo de atendimento onde cada colaborador da empresa, que nunca havia manuseado a ferramenta antes, teve que realizar três atividades: Cadastrar um novo paciente com seus dados, cadastrar novo solicitante com os dados preestabelecidos pelo avaliador e agendar um exame. O tempo de execução de cada tarefa por colaborador foi registrado, dando uma media de:

\section{Cadastrar paciente: 6,1 minutos;}

\section{Cadastrar solicitante: 3,2 minutos;}

\section{Agendar exame: 7,8 minutos;}

Durante a realização das tarefas foi possível observar que todos os novos usuários não tiveram problemas em encontrar a tela de cadastrar o paciente e solicitante. Por mais que o termo "solicitante" fosse desconhecido para eles, existe um ícone com o mesmo termo que não gera dúvidas. Alguns se enrolaram na hora de preencher as informações necessárias, pois a quantidade de informações é grande e não mostra o que é obrigatório de preencher. Uma mensagem de confirmação da tarefa mostrou-se necessária, pois os usuários não tiveram certeza se a operação foi concluída com sucesso. Em ambas as fichas cadastrais, existem espaços que o usuário só tem acesso a preencher após clicar uma vez em "salvar", o que gerou muita dúvida durante a realização das tarefas.

Durante a tarefa de agendamento os caminhos utilizados variaram e alguns necessitaram da ajuda da avaliadora para completar a tarefa. Apenas o primeiro usuário utilizou-se da tela de "recepção" para realizar o agendamento, que seria o caminho mais rápido. Os demais sempre eram direcionados as telas de "agendamento", uma mostra a agenda do médico em forma de lista e a outra em forma de calendário. Entre os 10 avaliados, 3 necessitaram da ajuda da avaliadora para finalizar a tarefa de agendar exame.

Após a realização das tarefas, um questionário foi aplicado a cada colaborador:

Resultado da Tabela SUS: O resultado do sistema SUS (System Usability Scale) recolhido com estes questionários foram de uma média de 53,15 pontos, um pouco acima da média. O resultado foi obtido com a média aritmética dos resultados de cada questionário, sendo eles $60,32,5,60,65,42,2,60,42,5,27,5,67,5,70,57,5$ pontos.

\subsubsection{Diagnóstico de Usabilidade}

Fazendo uma média aritmética de ambas as médias adquiridas ao longo do processo, tanto no questionário da Persona 1 quando no da Persona 2, temos o resultado de 
47,83 pontos. Sendo, assim, considerado um sistema pobre e insatisfatório ao usuário. Visto que as pontuações do SUS abaixo de 60 pontos representam sistemas pobres e insatisfação dos usuários, e pontuação acima de 80 representam experiências muito boas com alto índice de satisfação.

Após os resultados apresentados nos registros e análises feitas com usuários diários e novos usuários e no pré-diagnóstico foi possível constatar que o módulo de atendimento do UniClinika RIS possui todas as funcionalidades necessárias para o dia a dia das atendentes de uma clínica de diagnóstico por imagens, mas sem uma boa disposição e hierarquização das informações. Não é uma ferramenta intuitiva e peca na falta de feedbacks ao usuário.

Com os resultados dos pré-diagnósticos, questionários com os usuários e observações feitas durante o treinamento e realização das tarefas foi possível listar uma série de problemas a serem passados sobre o módulo de atendimento do UniClinika RIS. Tais problemas foram passados à empresa Ávila Solução no intuito de que haja ajustes para melhorar a usabilidade do sistema.

\section{CONCLUSÃO}

O estudo aqui proposto visou avaliar, seguindo os princípios de usabilidade de Jordan (1998), o modelo de usabilidade de Leventhal e Barnes (2008) e a heurística de Nielsen (1992), a ferramenta desktop UniClinika RIS mais especificamente o módulo de atendimento do sistema, versão mais recente. Como resultado, a análise da ferramenta se mostrou insatisfatória, mesmo tendo todas as funcionalidades necessárias para as clínicas de diagnóstico por imagem.

Durante o treinamento oferecido pela Ávila Soluções, realizado no dia 05 de maio de 2016, foi possível observar a dificuldade dos usuários para se adequarem as funcionalidades da ferramenta. Várias dúvidas foram levantadas durante o treinamento e mesmo após a explicação os usuários não se sentiram confiantes para usar a ferramenta por conta própria no dia a dia.

No segundo registro, realizado na empresa Ávila Soluções, durante a avaliação do módulo de atendimento onde cada colaborador da empresa, que nunca havia manuseado a ferramenta antes, teve que realizar três atividades: Cadastrar um novo paciente com seus dados, cadastrar novo solicitante com os dados preestabelecidos pelo avaliador e agendar um exame. Os resultados coletados mostraram que a ferramenta é simples, mas não é intuitiva e confunde o usuário com a falta de feedbacks e de descrições das atividades. O s dados coletados durante a realização das tarefas mostrou que o cadastramento de paciente e solicitante é bastante intuitivo, por terem ícones diretos, mas as informações obrigatórias não eram bem sinalizadas, nem tinham uma descrição de e a falta de feedbacks confundiu a todos ao final da tarefa. Mas durante o agendamento de exames houve vários problemas. O caminho mais fácil para agendar um exame seria pelo ícone "Recepção", mas a existência de dois ícones de "Agendamento" confundiu o usuário fazendo com que muitos tivessem dificuldade em finalizar a tarefa.

Os resultados dos questionários aplicados após o treinamento mostraram bastante à dificuldade que os usuários têm para com a ferramenta. E como eles são dependentes de memorizações de horários de médicos e de um suporte no dia a dia. Enquanto os questionários aplicados após a realização das tarefas mostrou que os usuários não 
acham a ferramenta complexa, mas afirmam que não é intuitiva e que sentiram falta dos feedbacks e informações de ajuda. Os resultados da tabela SUS aplicados no dia do treinamento apresentaram uma média muito abaixo, 28,33 pontos, enquanto a dos novos usuários mostrou uma média um pouco acima, 53,15 pontos. Dando uma média final um pouco abaixo, 47,83 pontos. O que mostra que melhorias e ajustes são necessários à ferramenta.

Como forma de melhorar o desempenho do sistema e a satisfação do usuário, o trabalho proposto listou os problemas encontrados que foram passados a empresa desenvolvedora para que fossem solucionados.

\section{REFERÊNCIAS BIBLIOGRÁFICAS}

FALCÃO, Christianne Soares; Usabilidade de Produtos de Consumo: uma análise dos conceitos, métodos e aplicações - 2013.

FERNANDES, Walquir da Silva; Verificação da conformidade das atuais Heuristicas de usabilidade quando aplicado aos equipamentos médicos de diagnostico por imagem. 2014. Dissertação (Programa de Pós-graduação em Design) - Universidade Federal de Pernambuco, Recife.

NETO, Edvar Vilar; A contribuição para uma nova usabilidade através da compilação de heurísticas para dispositivos com interação multimodal. 2013. Dissertação (Mestrado) Universidade Federal de Pernambuco, Recife.

ACIOLY, Angélica; TORRES, Caroline; ELOY, Cecília; SILVA, Ester; Análise de Usabilidade de Controles Remoto de Aparelhos de Ar condicionado Split. 2013. Trabalho final da disciplina Ergonomia e Usabilidade - Universidade Federal de Pernambuco, Recife.

BROOKE, John. SUS - A quick and dirty usability scale. Disponivel em: http://www.usabilitynet.org/trump/documents/Suschapt.doc Acesso em Mar.2013

LEVENTHAL, Laura; BARNES, Julie. Usability Engineering: process, products and example. USA: Pearson Prentice Hall. 2008.

JORDAN, Patrick W. An Introduction to Usability. London: Taylor \&amp; Francis. 1998. IIDA, ITIRO; Ergonomia: projeto e produção / Itiro lida - 2a edição ver. e ampl. - São Paulo: Blucher, 2005. $320 \mathrm{p}$.

\section{ANEXO 1 - QUESTIONÁRIO PERSONA 1}

Título da Pesquisa: Análise de Usabilidade do Produto UniClinika RIS

Objetivo da Pesquisa: Analisar a interação do usuário com o Módulo de Atendimento do UniClinika RIS, segundo princípios de usabilidade.

Integrantes do grupo: Cecília Eloy Neves.

Ferramenta a ser avaliada: UniClinika RIS - Módulo de Atendimento

PARTE 1 - DADOS PESSOAIS 
1 - Idade: menos de 20 anos ( ) 20-30 anos ( ) 31-40 anos ( ) 41-50 anos ( ) 51-60 anos ( ) mais de 60 anos ( )

2-Sexo: Feminino ( ) Masculino ( )

3 - Possui alguma deficiência/limitação? Não ( ) Sim ( ), qual?

4 - Profissão:

5 - Escolaridade: Ensino Fundamental Completo ( ） Ensino Fundamental Incompleto ( ) Ensino Médio Completo ( ) Ensino Médio Incompleto ( ) Ensino Superior Completo ( ) Ensino Superior Incompleto ( ) Pós-Graduação ( )

6 - Você já utilizou alguma outra ferramenta de agendamento de consultas antes? Não（） Sim（ ） Qual?

\section{PARTE 2 - INFORMAÇÕES SOBRE O USO DO UNICLINIKA RIS - MÓDULO DE ATENDIMENTO}

7 - Sobre o treinamento, o quão importante ele foi para você?

Não muito importante ( ) Minimamente importante ( ) Importante ( ) Muito importante ( ) Imprescindível para a realização da tarefa ( )

8 - Sobre as informações o layout e disposição das informações, você considera de FÁCIL COMPREENSÃO?

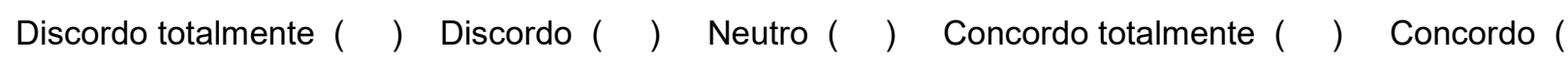

9 - Sobre as informações (pictográficas e/ou textuais) exibidas no layout do Módulo de Atendimento, você as considera de FÁCIL COMPREENSÃO?

Discordo totalmente ( ) Discordo ( ) Neutro ( ) Concordo totalmente ( ) Concordo ( )

9.1 Que tipo de problema você identifica nessas informações?

Legibilidade ( ) Entendimento do seu significado ( ) Dimensionamento ( ) Cor/Contraste ( ) Quantidade das informações ( ) Outro ( ) qual?

10 - Sobre o feedback fornecido pelo Módulo de Atendimento durante o acionamento das funções do programa, você o considera ADEQUADO?

Discordo totalmente ( ) Discordo ( ) Neutro ( ) Concordo totalmente ( ) Concordo ( )

11 - Sobre a sua satisfação quanto ao uso do módulo de atendimento, responda as questões a seguir: (System Usability Scale, @ Digital Equipment Corporation, 1986)

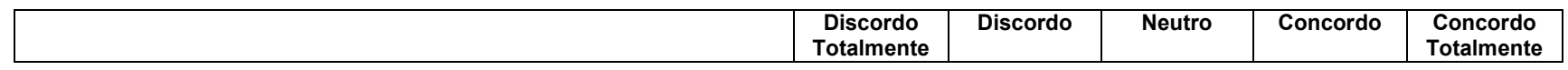




\begin{tabular}{|l|l|l|l|l|l|}
\hline $\begin{array}{l}\text { 1. Acho que gostaria de usar esse sistema com } \\
\text { frequência }\end{array}$ & 1 & & & & \\
\cline { 2 - 6 }
\end{tabular}

2. Achei o sistema desnecessariamente complexo

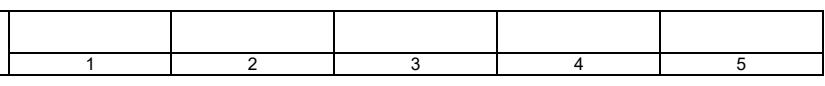

\begin{tabular}{|l|l|l|l|l|l|}
\hline 3. Achei o sistema fácil de usar & & & & & \\
\cline { 2 - 5 }
\end{tabular}

\begin{tabular}{|l|l|l|l|l|}
\hline $\begin{array}{l}\text { 4. Achei que seria necessário o apoio de um técnico } \\
\text { para poder usar este sistema }\end{array}$ & & & & \\
\cline { 2 - 5 }
\end{tabular}

\begin{tabular}{|l|l|l|l|l|l|}
\hline 5. As funções deste sistema estavam bem integradas & & & & & \\
\cline { 2 - 4 } & & 1 & 2 & 3 & 4 \\
\hline
\end{tabular}

\begin{tabular}{|l|l|l|l|l|l|}
\hline 6. Achei este sistema muito inconsistente & & & & & \\
\hline
\end{tabular}

\begin{tabular}{|l|l|l|l|l|}
\hline 7.Imagino que a maioria das pessoas aprenderiam a & & & & \\
usar este sistema rapidamente & 1 & 2 & & 3 \\
\hline
\end{tabular}

\begin{tabular}{|l|l|l|l|l|l|}
\hline 8. Achei este sistema muito complicado de usar & & & & & \\
\cline { 2 - 4 }
\end{tabular}

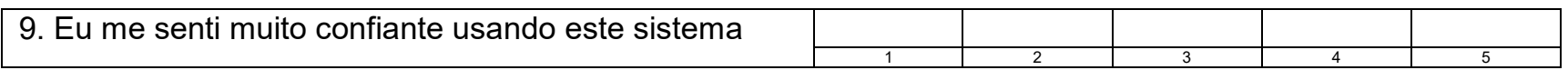

\begin{tabular}{|l|l|l|l|l|l|}
\hline 10. Eu precisaria aprender um monte de coisas antes & & & & & \\
\cline { 3 - 6 } de continuar usando este sistema & ${ }^{1}$ & ${ }^{2}$ & ${ }^{3}$ & ${ }^{4}$ & 5 \\
\hline
\end{tabular}

Qual sua opinião sobre este Módulo/Sugestões?

Obrigado por sua participação nesta pesquisa.

\section{ANEXO 2 - QUESTIONÁRIO PERSONA 2}

Título da Pesquisa: Análise de Usabilidade do Produto UniClinika RIS

Objetivo da Pesquisa: Analisar a usabilidade do modulo de atendimento do UniClinika RIS para listar os principais problemas.

Integrantes do grupo: Cecília Eloy Neves.

Tipo de controle avaliado: UniCilika RIS - Módulo de Atendimento 
1 - Idade: menos de 20 anos（） 20-30 anos（） 31-40 anos（） 41-50 anos（） 51-60 anos（） mais de 60 anos ( )

2 - Sexo: Feminino ( ) Masculino ( )

3 - Possui alguma deficiência/limitação? Não ( ) Sim ( ), qual

4 - Profissão:

5 - Escolaridade:

Ensino Fundamental Completo ( ） Ensino Fundamental Incompleto ( ） Ensino Médio

Completo ( ) Ensino Médio Incompleto ( ) Ensino Superior Completo ( ) Ensino

Superior Incompleto ( ) Pós-Graduação ( )

6 - Sobre a sua satisfação quanto ao uso do módulo de atendimento, responda as questões a seguir:

(System Usability Scale, @ Digital Equipment Corporation, 1986)

\begin{tabular}{|c|c|c|c|c|c|}
\hline & $\begin{array}{c}\text { Discordo } \\
\text { Totalmente }\end{array}$ & Discordo & Neutro & Concordo & $\begin{array}{c}\text { Concordo } \\
\text { Totalmente }\end{array}$ \\
\hline \multirow{2}{*}{$\begin{array}{l}\text { 1. Acho que gostaria de usar esse sistema com } \\
\text { frequência }\end{array}$} & & & & & \\
\hline & 1 & 2 & 3 & 4 & 5 \\
\hline
\end{tabular}

2. Achei o sistema desnecessariamente complexo

\begin{tabular}{|l|l|l|l|l|l|}
\hline 3. Achei o sistema fácil de usar & & & & & \\
\cline { 2 - 5 }
\end{tabular}

\begin{tabular}{|l|l|l|l|l|}
\hline $\begin{array}{l}\text { 4. Achei que seria necessário o apoio de um técnico } \\
\text { para poder usar este sistema }\end{array}$ & & & & \\
\cline { 2 - 5 }
\end{tabular}

\begin{tabular}{|l|l|l|l|l|l|}
\hline 5. As funções deste sistema estavam bem integradas & & & & & \\
\cline { 2 - 4 } & & 1 & 2 & 3 & 4 \\
\hline
\end{tabular}

\begin{tabular}{|l|l|l|l|l|l|}
\hline 6. Achei este sistema muito inconsistente & & & & & \\
\cline { 2 - 4 } & 1 & 2 & 3 & 4 \\
\hline
\end{tabular}

7.Imagino que a maioria das pessoas aprenderiam a usar este sistema rapidamente

\begin{tabular}{|l|l|l|l|l|l|}
\hline 8. Achei este sistema muito complicado de usar & & & & & \\
\cline { 2 - 4 } & & 1 & 2 & 3 & 5 \\
\hline
\end{tabular}

9. Eu me senti muito confiante usando este sistema

\begin{tabular}{|l|l|l|l|l|}
\hline & & & & \\
\hline 1 & 2 & 3 & 4 & 5 \\
\hline
\end{tabular}

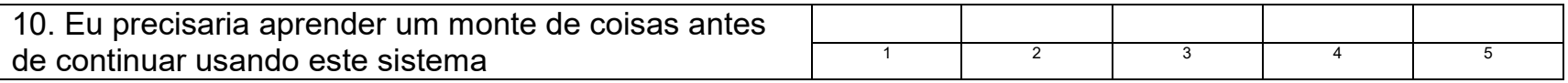

Qual sua opinião sobre este Módulo/Sugestões? 
Obrigado por sua participação nesta pesquisa.

ANEXO 3 - FLUXOGRAMA DO UNICLINIKA RIS

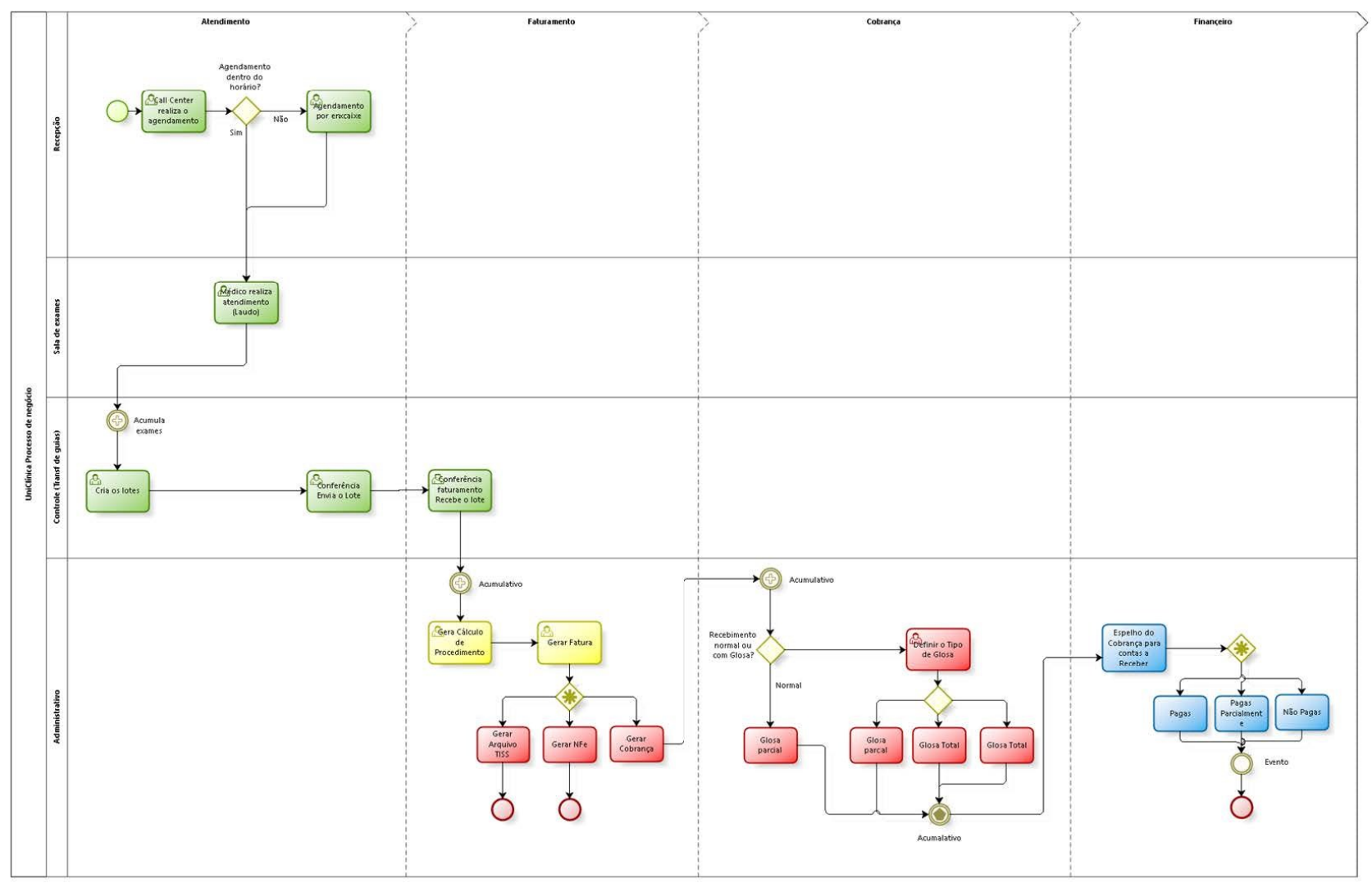

